\title{
Maturation of somatomotor responses
}

\section{to strychnine in the albino rat}

\author{
E. ENGELHARDT AND C. A. ESBÉRARD
}

Department of Histology and Embryology, Faculdade de Medicina, Universidade Federal do Rio de Janeiro, and Laboratory of Neurophysiology, Instituto Oswaldo Cruz, Rio de Janeiro, Brazil

1. The maturation of the convulsogenic activity of the caudal brainstem and spinal cord in the developing albino rat was studied by intraperitoneal injections of strychnine sulphate.

2. The observed responses were classed as hyperexcitability and hypertonic responses, graded 1 to 4 . The complete tonic seizure (grade 4 hypertonic reaction, strychnine tetanus, maximal response) was obtained in all age groups, from birth to adulthood. The responses were grouped in sequences, and two patterns were distinguished: an infant one (from birth to 3 weeks) and an adult one (from 3 weeks on).

3. All doses varied according to age. The curve obtained for the median convulsive dose falls into two parts: descending, from birth to 3 weeks, and ascending, from 3 weeks on. Each part corresponded to a sequence pattern, the descending one to the infant pattern, and the ascending one to the adult pattern.

4. From these patterns and the corresponding median effective doses, three stages of the convulsogenic maturation of the spinal cord were distinguished: immaturity, pharmacological maturity and convulsogenic maturity.

5. It is suggested that the mechanism responsible for the complete tonic seizure is fully functional from birth, while that responsible for clonic seizure only reaches full maturity at 3 weeks of age.

The convulsogenic activity of the caudal brainstem and spinal cord can be elicited by the use of strychnine (Pike, 1909 ; Poulsson, 1920 ; Dusser de Barenne, 1933 ; Brémer, 1941, 1949, 1953 ; Gernandt \& Terzuolo, 1955 ; Sollmann, 1957 ; Gastaut \& Fischer-Williams, 1959 ; Eccles, 1964). The resulting hypersynchronized discharge produces a sustained contraction of the antigravitarian muscles (Brémer, 1941, 1949, 1953; Gastaut \& Fischer-Williams, 1959). This is an observable somatomotor response which can be used as an index of the activity of the nervous system. The observation of the responses induced by strychnine on a developing animal permits the assessment of the maturational stages of the stimulated regions from the type of responses and the age of which they appear. The present paper describes the results of such an analysis on the immature albino rat. 
Several reports dealing with the effects of strychnine on immature animals have been published. In addition to the pioneer observations of Bert (1870) and Lau (1886) on the cat and the dog, Falck $(1884,1885)$ described its effects on the mouse, rabbit and guinea-pig, and Schwartze (1922) and Pilkkö \& Woodbury (1961) on the rat. These reports established a variation in sensitivity with age, younger animals being less susceptible than mature ones. Preliminary communications of some of our results have already been published (Engelhardt \& Esbérard, 1966 ; Esbérard \& Engelhardt, 1966).

\section{Methods}

A total of 510 albino rats of both sexes (Wistar strain) were distributed into six age groups (Table 1). Groups of six to ten animals were observed at every session. A set of records was made by each author for each animal throughout the observation period and a final record was established when these had been compared. Each rat was used once only, to avoid responses caused by modification of the animal's reactivity (Weiss \& Hatcher, 1922).

Although a differential sensitivity to strychnine in relation to sex has been reported (Poe, Suchy \& Witt, 1936; Ward \& Crabtree, 1942; Kato, Chiesara \& Frontino, 1962 ; Lakatos, Vacher \& Duchêne-Marullaz, 1964), this becomes evident only after the completion of sexual development (Hurst, 1958 ; Kato, Chiesara \& Frontino, 1962). Our study was based almost entirely on prepubertal animalspuberty in the rat occurring between 40 days (male, descent of testis, Farris, 1942) and 46-47 days (female, opening of vagina, Luce-Clausen \& Brown, 1939 ; Donovan $\&$ van der Werff ten Bosch, 1965)-so we felt that these differences could be disregarded, for only part of one of our experimental groups (5-8 weeks), besides the adult control group, exhibited such differences. In all experiments, strychnine sulphate was used in concentrations of 0.01 to $0.1 \mathrm{~g} / 100 \mathrm{ml}$., injected intraperitoneally in doses between 0.5 and $10.0 \mathrm{mg} / \mathrm{kg}$. In newborn and 1 week old animals the skin had minimal elasticity, and the injections were made through a small strip of plastic adhesive applied to the abdominal wall, to avoid reflux of the injected solution through the needle puncture. The median effective doses were calculated according to the method described by Bliss $(1935 \mathrm{a}, \mathrm{b})$.

\begin{tabular}{lcccc}
\multicolumn{1}{c}{$\begin{array}{c}\text { Age } \\
\text { group }\end{array}$} & $\begin{array}{c}\text { Tabe 1. } \\
\text { (days) }\end{array}$ & $\begin{array}{c}\text { Characteristics of animals used } \\
\text { Number of } \\
\text { animals }\end{array}$ & $\begin{array}{c}\text { Number of } \\
\text { litters }\end{array}$ & $\begin{array}{c}\text { Weight } \\
(\mathrm{g})\end{array}$ \\
First week & $1-3$ & 119 & 22 & $\begin{array}{c}5 \cdot 55 \pm 0 \cdot 89 \\
(3 \cdot 5-8 \cdot 0)\end{array}$ \\
Second week & $6-8$ & 130 & 20 & $\begin{array}{c}8 \cdot 45 \pm 2 \cdot 04 \\
(4 \cdot 5-15 \cdot 0)\end{array}$ \\
Third week & $13-15$ & 99 & 15 & $\begin{array}{c}15 \cdot 90 \pm 3 \cdot 89 \\
(8 \cdot 0-27 \cdot 0)\end{array}$ \\
Fourth week & $20-22$ & 49 & 10 & $\begin{array}{c}20 \cdot 46 \pm 5 \cdot 33 \\
(12 \cdot 0-37 \cdot 0)\end{array}$ \\
Fifth-eighth week & $27-29$ & 52 & 11 & $\begin{array}{l}31 \cdot 67 \pm 7 \cdot 96 \\
(14 \cdot 0-53 \cdot 0)\end{array}$ \\
Adult & $34-57$ & 33 & 7 & $\begin{array}{l}68 \cdot 10 \pm 12 \cdot 04 \\
(28 \cdot 0-110 \cdot 0) \\
176 \cdot 40 \pm 28 \cdot 90 \\
(110 \cdot 0-220 \cdot 0)\end{array}$
\end{tabular}

Age in days refers to range in each group. Weight values are given as average $\perp$ S.D. Values in brackets refer to range of body weight variation in each group. 


\section{Results}

\section{Somatomotor responses}

The responses observed were classed as " hyperexcitability" (obtained after application of different kinds of stimuli) and "hypertonic reactions" (occurring spontaneously) of grades 1 to 4 , according to intensity. Short descriptions of the chief characteristics of the observed responses and the order in which they appeared are presented in Table 2 .

Two phases in the sequence of responses were observed according to dose: a convulsive one, with high doses, when the complete sequence was obtained, comprising initial hyperexcitability followed by hypertonic reactions of grades 1

\section{Responses \\ Hyperexcitability (after stimulus) \\ 1-2 minutes after injection}

Hypertonic reactions ("spontaneous") Grade 1

Grade 2

Grade 3

Grade 4

6-10 min after injection

TABLE 2. Sequences of responses to strychnine

$$
\text { Infant pattern }
$$

Repetitive episodes of slow extension of head and limbs, and eventual loss of quadruped posture.

Repetitive episodes of slow extension of head, trunk and limbs, interrupted by periods of relaxation.

Hypertonic progression: all segments in maximum extension and slow progression by simultaneous movements of forelimbs. Contortions: after hypertonic progression, loss of quadruped posture and inco-ordinated movements of head, trunk, tail and limbs; mainly in the younger animals; in short or prolonged episodes.

Hindlimb tonic extension: loss of quadruped posture, tonic extension of axial structures and hindlimbs, and slow alternating movements of the extended forelimbs.

Tonic spasm: the movements of the forelimbs in hindlimb tonic extension are interrupted and slowly extended caudalward, immediately followed by relaxation; repetitive; frequent.

Complete tonic seizure: after hindlimb tonic extension or tonic spasm, extension of axial structures and caudalward extension of the limbs; posture maintained for 5-30 sec; relaxation and depression. Followed by: tonic-clonic phase (events that occur after the first complete tonic seizure): consisting of complete tonic seizures, clonic seizures, tonic spasms and quiescent periods; prolonged, for $1 \mathrm{hr}$ or more.

Clonic seizure: non-rhythmic and slow movements of head and limbs, in the first week, progressing to rhythmic and rapid by the third week; prolonged episodes.

\section{Adult pattern}

Single episode of extension of head, with rapid abduction of the limbs.

Extension of tail and slightly spastic gait.

Hypertonic progression: head, trunk, tail and limbs in extreme extension and rapid progression by alternating movements of the limbs.

Hindlimb tonic extension, with same posture and rapid alternating movements of the forelimbs.

Tonic spasm, with same characteristics, very rare.

Complete tonic seizure: after rapid hypertonic progression or hindlimb tonic extension, with same characteristics as in the infant stage.

Tonic-clonic phase: consisting of clonic seizures, rare tonic spasms and periods of quiescence; short, for about $5 \mathrm{~min}$.

Clonic seizure: rhythmic and rapid alternating movements of flexion-extension of head and limbs; short episodes. and after grade 4 hypertonic reaction in convulsive sequence. 
to 4, appearing successively, one after the other ; and a non-convulsive one, with low to median doses, in which the sequence included, after the hyperexcitability period, hypertonic reactions of grade 1 , or of grades 1 and 2, or of grades 1,2 and 3 (Table 2). After the reaction period the animal gradually recovered. When the highest experimental doses for each group were used, the animal occasionally died during the reaction period. This happened chiefly with the older animals and very seldom with the younger ones.

According to age, two patterns of responses were observed, one appearing in animals from birth up to 3 weeks of age (the infant pattern), and another in animals from 3 weeks on (the adult pattern) (Table 2).

The infant pattern was characterized by a hyperexcitability period followed by repetitive hypertonic reactions of grades 1 to 3 , complete tonic seizure (grade 4 reaction) and a prolonged tonic-clonic phase, with ill-defined clonic episodes and additional complete tonic seizures. The adult pattern presented a hyperexcitability period, hypertonic responses of grades 1 to 3, a complete tonic seizure and a short tonic-clonic phase with well defined clonic seizures and absence of further complete tonic seizure.

\section{Variation of median effective doses with age}

The values of the median effective doses are listed in Table 3. The curve expressing the variation of the median convulsive dose is in two parts, a descending one, from birth to 3 weeks, and an ascending one, from 3 weeks to adulthood (Fig. 1 , filled circles). The values of the median effective doses for the hypertonic reactions of grades 1 to 3 were estimated only in the initial age groups (Table 3 and Fig. 1). There was a wide variation in the effective dose of hypertonic reactions in the youngest animals, the effective doses converging towards the mean by week 3 .

The data presented in Table 3 and Fig. 1 show a variation of sensitivity in relation to age. This variation can be estimated, for each age group, in relation to the adult median convulsive dose. The resulting curve presents two regions, one in which 2 or 3 times the adult dose is required, comprising the newborn to 10-11 days (1.5 weeks) old, and another requiring less than half the adult dose, related to animals 10-11 days of age onwards (Fig. 2A). The same pattern is obtained in the curve expressing the variation of the median convulsive doses in

\begin{tabular}{|c|c|c|c|c|}
\hline \multirow{4}{*}{$\begin{array}{l}\text { Age group } \\
\text { Newborn }\end{array}$} & \multicolumn{4}{|c|}{ Median effective doses for hypertonic reactions } \\
\hline & Grade 1 & Grade 2 & Grade 3 & Grade 4 \\
\hline & $\begin{array}{c}0 \cdot 70 \\
(0 \cdot 16-1 \cdot 24)\end{array}$ & $\begin{array}{c}1 \cdot 78 \\
(1 \cdot 41-2 \cdot 15)\end{array}$ & $\begin{array}{c}3 \cdot 58 \\
(3 \cdot 21-3 \cdot 95)\end{array}$ & $\begin{array}{c}7 \cdot 25 \\
(5 \cdot 49-9 \cdot 01)\end{array}$ \\
\hline & - & $\begin{array}{c}1 \cdot 05 \\
(0 \cdot 84-1 \cdot 26)\end{array}$ & $\begin{array}{c}2 \cdot 56 \\
(2 \cdot 42-2 \cdot 70)\end{array}$ & $\begin{array}{c}3 \cdot 49 \\
(2 \cdot 70-4 \cdot 28)\end{array}$ \\
\hline Second week & - & $\begin{array}{c}0.63 \\
(0.28-0.98)\end{array}$ & $\begin{array}{c}0 \cdot 74 \\
(0.42-1 \cdot 06)\end{array}$ & $\begin{array}{c}0.89 \\
(0.76-1.02)\end{array}$ \\
\hline Third week & - & - & - & $\begin{array}{c}0.72 \\
(0.71-0.73)\end{array}$ \\
\hline Fourth week & - & - & - & $\begin{array}{c}1 \cdot 32 \\
(1 \cdot 25-1 \cdot 39)\end{array}$ \\
\hline Fifth-eighth week & - & - & - & $\begin{array}{c}1 \cdot 74 \\
(1 \cdot 42-2 \cdot 06)\end{array}$ \\
\hline Adult & 一 & - & - & $\begin{array}{c}2 \cdot 13 \\
(2 \cdot 10-2 \cdot 16)\end{array}$ \\
\hline
\end{tabular}

Values in brackets are the fiducial limits for chance sampling variation odds of 1 in 20 (Bliss, $1935 \mathrm{~b}$ ). 


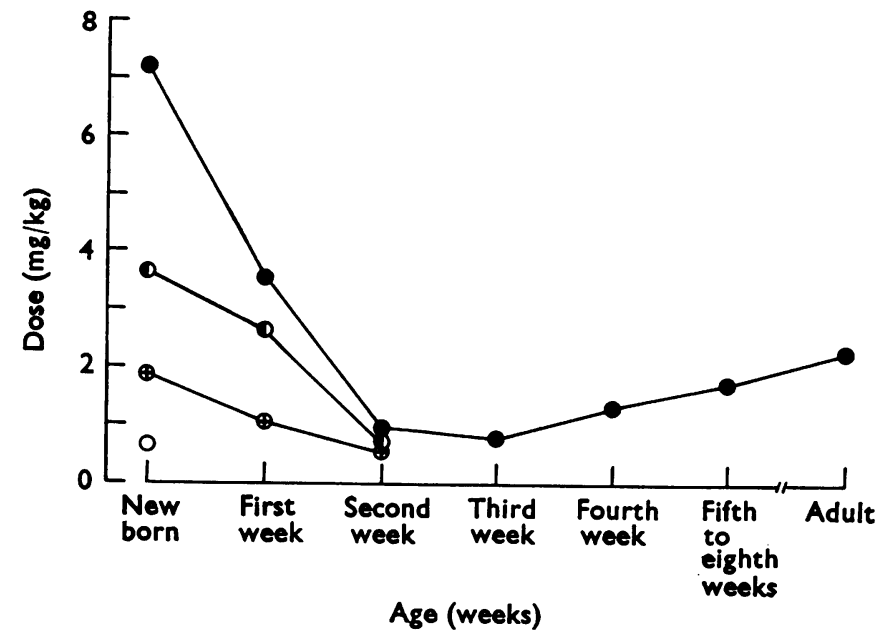

FIG. 1. Median doses of strychnine sulphate for production of hypertonic reactions (grades 1 to 4), plotted against age, in the developing rat. $\bigcirc$, grade $1 ; \oplus$, grade $2 ; 0$, grade 3 ; grade 4.
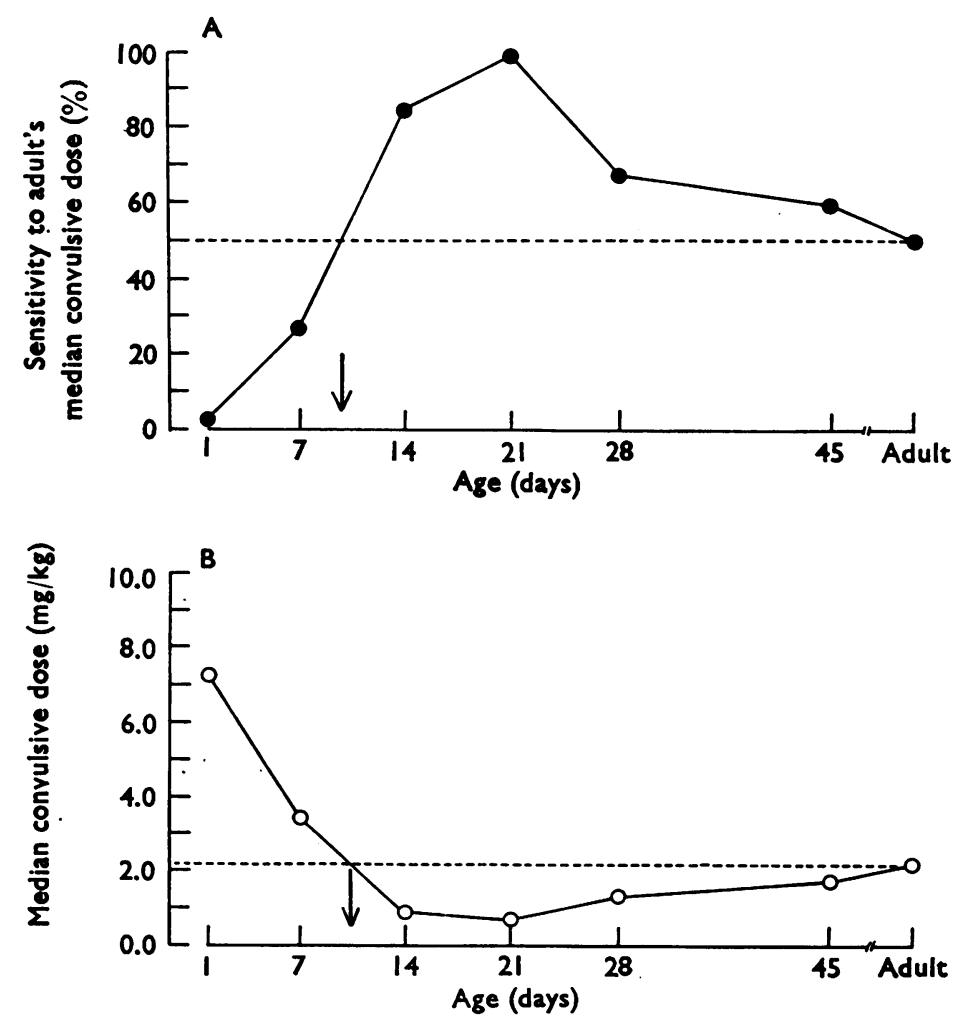

FIG. 2. A : Variation of sensitivity in relation to the adult median convulsive dose in each age group. Arrow marks the age in which a sensitivity similar to the adult is reached. B: Median convulsive dose in relation to age. Arrow marks the age in which the value of the adult first occurs. 
relation to age by assessing when the adult value for the median convulsive dose first occurs (Fig. 2B). During post-natal development, this age (10-11 days or 1.5 weeks) marks the moment when the rat first reacts maximally to the effective adult dose of strychnine, but with responses of the infant pattern.

\section{Discussion}

The observed somatomotor responses were grouped in a sequence of hyperexcitability, followed by hypertonic reactions (grades 1 to 3), complete tonic seizure (grade 4) and tonic-clonic phase. Two patterns were distinguishable, an infant one, and an adult one (Table 2). A similar sequence was described by Fühner (1911) and Poulsson (1920) in the frog, and by Falck $(1884,1885)$ in the mouse, rabbit and guinea-pig. The latter also observed different patterns according to age. Pilkkö $\&$ Woodbury (1961) described several reactions in the developing rat. The maximal tonic response, a complete tonic seizure, was observed by Falck $(1884,1885)$ in the mouse, rabbit and guinea-pig, in all age groups, and by Schwartze (1922) in 6 and 10 day old and older rats. We have observed it in all age groups. Pilkkö \& Woodbury (1961) noted that the complete tonic seizure did not occur in rats less than 12-16 days old, and interpreted these results as due to the immaturity of the rats. In newborn to 2 week old animals, they considered, as maximal effects, responses similar to our grades 1-2 hypertonic responses. The doses they used to obtain these effects were similar to those we employed to induce the reactions of grades 1-2. Vernadakis (1962) recorded tonic convulsions by direct electric stimulation of the spinal cord in decapitated rats. This author observed tonic convulsions from birth which from the twelfth day on were elicited with the same frequency as in the adult, showing the ability of the spinal cord to produce tonic convulsions at low ages.

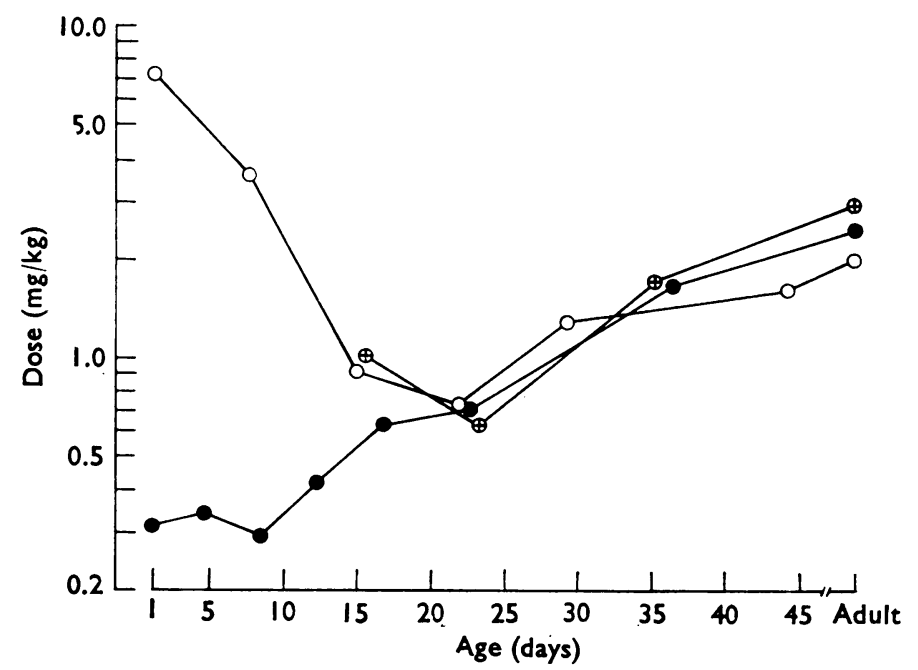

FIG. 3. Dose/age curves for the complete tonic seizure induced by strychnine on the rat. Values from present report $(\bigcirc)$, from Schwartze (1922) (甲), and Pilkkö \& Woodbury (1961) (O). Values of Schwartze are average median convulsive doses, the others are median convulsive doses. 
In our observations the convulsive doses varied with age. The highest median convulsive dose was necessary in newborn animals and the lowest in 3 weeks old animals, with the adult value between the two. The resulting curve was divided into two parts (Figs. 1 and 2), a descending one, from birth to 3 weeks of age, and an ascending one, from 3 weeks of age to adulthood. Each part corresponded to a sequence pattern, the descending one to the infant pattern, characteristic of the immature animal, and the ascending one to the adult pattern, observed in the mature animal. An intermediate phase was also defined by the projection of the adult median convulsive dose on the descending part (Fig. 2B). This corresponds to the age of 1.5 weeks (10-11 days), when the animals, although immature, respond maximally to adult doses. The results for immature animals at birth (rat, mouse and rabbit) (Falck, 1884, 1885 ; Schwartze, 1922 ; present report) show similar curves, with an initial descending part, followed by an ascending one, permitting the projection of the adult value on the descending limb and the determination of the moment when it appears for the first time (Fig. 3 and 4). The degree of immaturity at birth of each species differs, as demonstrated by the different ages of occurrence of the lowest median convulsive dose (maximum sensitivity) (Figs. 3 and 4).

For the guinea-pig, a species born relatively mature, the maximum sensitivity occurs at birth, and decreases progressively (Falck, 1885). In other words, only the ascending part of the curve is shown, characteristic of the mature animal (Fig. 4, open circles). The descending part, characteristic of the immature animal, should be obtained in the pre-natal period, in view of the fact that at 30-35 days of gestation the guinea-pig presents a similar degree of maturity to that of a newborn rat (Eayrs \& Goodhead, 1959 ; Martin, 1962).

Pilkkö \& Woodbury (1961) obtained results which give only an ascending curvethe mature curve (Fig. 3, filled circles). In this case, it should be possible to obtain a descending curve from the pre-natal rat, in which the projection of the adult median convulsive dose would occur at an age when the animal would be much more immature than at birth and less able to respond with a complete tonic seizure. Furthermore, the part of the curve which corresponds to animals from

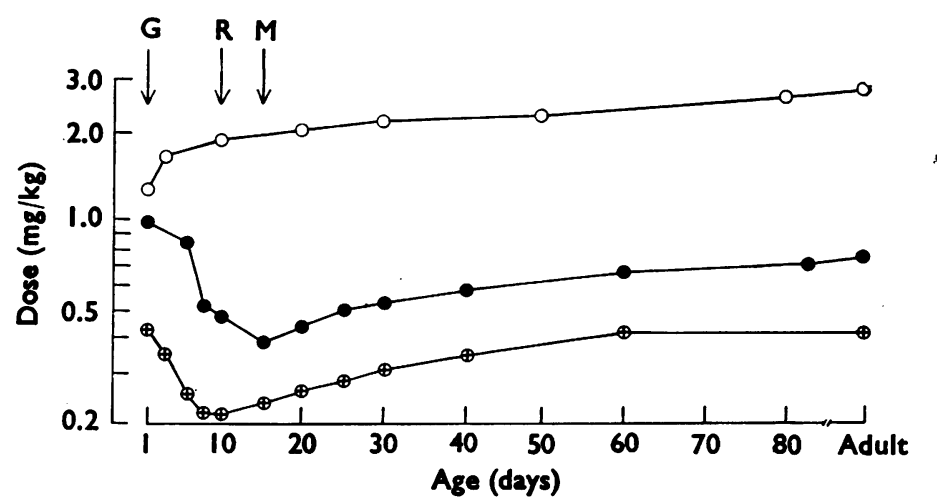

FIG. 4. Dose/age curves for the complete tonic seizure induced by strychnine. All data from Falck $(1884,1885)$ : guinea-pig $(\bigcirc)$, mouse $(O)$ and rabbit $(\oplus)$. Arrows mark the ages of occurrence of the lowest value of the convulsive dose for the guinea-pig (G), rabbit (R) and mouse $(\mathbf{M})$. All values are the minimum convulsive doses. 
birth until 3 weeks is heterogeneous, for the authors use as maximal responses several reactions of different intensities. The part of their curve corresponding to animals of more than 3 weeks of age agrees with the other results (Fig. 3).

The sites of strychnine action are the caudal brainstem, and principally the spinal cord (Poulsson, 1920; Dusser de Barenne, 1933; Brémer, 1941, 1949, 1953 ; Sollmann, 1957 ; Gastaut \& Fischer-Williams, 1959), and the major convulsive patterns are integrated by spinal reflex mechanisms (Esplin \& Laffan, 1957 ; Esplin, 1959). The correlation of the patterns of the convulsive sequences with the median doses necessary for their production enables the maturation of the convulsogenic activity of the caudal brainstem and spinal cord to be divided into three stages:

1. Immaturity (from birth to 1.5 weeks of age) in which the animals only present responses in the infant pattern with doses higher than those necessary in the adult.

2. Pharmacological maturity (from 1.5 to 3 weeks of age) in which the animals still respond in the infant pattern to doses equal to or lower than those effective in the adult. Another sign of immaturity is the dissociation between the convulsive and non-convulsive doses, which is not seen in the mature stage.

3. Convulsogenic maturity (from 3 weeks of age to adulthood) in which the animals respond in the adult pattern to doses effective in the adult.

The complete tonic seizure was qualitatively similar in all age groups, suggesting that the reticulospinal mechanism responsible (Gastaut \& Fischer-Williams, 1959) is active from birth, although with a low sensitivity, and acquires adult sensitivity at the second stage (pharmacological maturity). The clonic seizure presents its definitive characteristics in 3 week old animals, suggesting that the neuromuscular mechanism responsible (Cobb, 1924; Vianna Dias, 1954) is mature at the third stage (convulsogenic maturity).

This work was supported by the Conselho Nacional de Pesquisas and C.A.P.E.S.

\section{REFERENCES}

BerT, P. (1870). Cited in Schwartze, E. W. (1922). Functional evidence of the phylogeny of the nervous system as shown by the behavior and resistance of the developing rat to strychnine. J. Pharmac. exp. Ther., 19, 273-291.

Buiss, C. I. (1935a). The calculation of the dosage-mortality curve. Ann. appl. Biol., 22, 134-167.

Busss, C. I. (1935b). The comparison of dosage-mortality data. Ann. app!. Bio!., 22, 307-333.

BrémER, F. (1941). Le tétanos strychnique et le mécanisme de la synchronisation neuronique. Arch. int. Physiol., 51, 211-260.

Brémer, F. (1949). The functional synergy of the spinal cord in strychnine tetanus. Trans. Am. neurol. Ass., 74, 222-223.

Brémer, F. (1953). Strychnine tetanus of the spinal cord. In The Spinal Cord, ed. Malcolm, J. L. \& Gray, J. A. B., pp. 78-83. Boston: Little, Brown and Company.

Совв, S. (1924). Electromyographic studies of experimental convulsions. Brain, 47, 70-75.

Donovan, B. T. \& VAN Der Werff ten Bosch, J. J. (1965). Physiology of Puberty, pp. 21-37. London: Edward Arnold.

DUSSER DE BARENNE, J. G. (1933). The mode and site of action of strychnine in the nervous system. Physiol. Rev., 13, 325-335.

EAYRS, J. T. \& GoODHEAD, B. (1959). Post-natal development of the cerebral cortex in the rat. J. Anat., 93, 385-402.

EcCles, J. C. (1964). The Physiology of Synapses, pp. 189-215. New York: Academic Press.

ENGELhARDT, E. \& ESBÉRARD, C. A. (1966). Ontogenesis of convulsogenic activity of the albino rat spinal cord. 3rd Int. Congr. Pharmac. (S. Paulo), Summaries, pp. 97-98.

Esbérard, C. A. \& ENGelHardt, E. (1966). Strychnine induced activity in the rat: age-dose relationships. Ann. Acad. bras. Ciências, 38, 578-R.

Esplin, D. W. (1959). Spinal cord convulsions. A.M.A. Archs Neurol., 1, 485-490.

Esplin, D. W. \& LAFFAN, R. J. (1957). Determinants of flexor and extensor components of maximal seizures in cats. Archs int. Pharmacodyn. Thér., 113, 189-202. 
FALCK, F. A. (1884). Ueber den Einfluss des Alters auf die Wirkung des Strychnins, I. Pflügers Arch. ges. Physiol., 34, 530-575.

FALCK, F. A. (1885). Ueber den Einfluss des Alters auf die Wirkung des Strychnins, II. Pflügers Arch. ges. Physiol., 36, 285-308.

FARRIS, E. J. (1942). Breeding of the rat. In The Rat in Laboratory Investigation, ed. Griffith, J. Q. \& Farris, E. J., pp. 1-17. Philadelphia: Lippincott.

FüHNER, H. (1911). Cited in Poulsson, E. (1920). Die Strychninegruppe. I. Strychnin. In Handbuch der Experimentellen Pharmackologie, ed. Heffter, A., vol. 2 (part 1), pp. 322-388. Berlin: Springer-Verlag.

Gastaut, H. \& Fischer-Williams, M. (1959). The physiopathology of epileptic seizures. In Handbook of Physiology, ed. Field, J., \& Magoun, H. W., Neurophysiology, vol. 1, pp. 329-363. Washington: American Physiological Society.

GernANDT, B. E. \& Terzuolo, C. A. (1955). Effect of vestibular stimulation on strychnine-induced activity of the spinal cord. Am. J. Physiol., 183, 1-8.

HURST, E. W. (1958). Sexual differences in the toxicity and therapeutic action of chemical substances. In The Evaluation of Drug Toxicity, ed. Walpole, A. L. \& Spinks, A., pp. 12-22. London: Churchill.

Kato, R., Chiesara, E. \& Frontino, G. (1962). Influence of sex difference on the pharmacological action and metabolism of certain drugs. Biochem. Pharmac., 11, 221-227.

lakatos, C., Vacher, J. \& DuchÉne-Marullaz, P. (1964). Différence de toxicité de la strychnine suivant le sexe chez la souris. Application pharmacodynamique. C.r. Soc. Biol., 158, 544-546.

LAU, B. (1886). Cited in Schwartze, E. W. (1922). Functional evidence of the phylogeny of the nervous system as shown by the behavior and resistance of the developing rat to strychnine. J. Pharmac. exp. Ther., 19, 273-291.

LuCe-Clausen, E. M. \& Brown, E. F. (1939). The use of isolated radiation in experiments with the rat. III. Effects of darkness, visible and infrared radiation on three succeeding generations of rats. (b) Reproduction. J. Nutr., 18, 551-562.

MARTIN, R. (1962). Entwicklungszeiten des Zentralnervensystems von Nagern mit Nesthockerund Nestfluechterontogenese. Revue suisse Zool., 69, 617-727.

PIKE, F. H. (1909). Studies in the physiology of the central nervous system. I. The general phenomena of spinal shock. Am. J. Physiol., 24, 124-152.

PoE, C. F., SuChY, J. F. \& WITT, N. F. (1936). Toxicity of strychnine for male and female rats of different ages. J. Pharmac. exp. Ther., 58, 239-242.

Poulsson, E. (1920). Die Strychningruppe. I. Strychnin. In Handbuch der Experimentellen Pharmakologie, ed. Heffter, A., vol. 2 (part 1), pp. 322-388. Berlin: Springer-Verlag.

PilkKö, O. O. \& WoOdBURY, D. M. (1961). The effect of maturation on chemically-induced seizures in rats. J. Pharmac. exp. Ther., 131, 185-190.

SCHWARTZE, E. W. (1922). Functional evidence of the phylogeny of the nervous system as shown by the behavior of the developing rat to strychnine. J. Pharmac. exp. Ther., 19, 273-291.

SollmanN, T. (1957). Convulsant poisons: strychnine and Nux vomica. In A Manual of Pharmacology, 8th ed., pp. 232-243. Philadelphia: Saunders.

Vernadakis, A. (1962). Spinal cord convulsions in developing rats. Science, N.Y., 137, 532.

VianNa Dias, M. U. (1954). Estudo miográfico das convulsões epileptiformes produzidas pela excitação da córtex cerebral. Ann. Acad. bras. Ciências, 26, 475-529.

WARD, J. C. \& CrabTREe, D. G. (1942). Strychnine. X. Comparative accuracies of stomach tube and intraperitoneal injection methods of bioassay. J. Am. pharm. Ass., 31, 113-115.

Weiss, S. \& Hatcher, R. A. (1922). Studies on strychnine. J. Pharmac. exp. Ther., 19, 419-482.

(Received March 14, 1966) 